\title{
Successful Treatment of Diabetic Ketoacidosis and Hyperglycemic Hyperosmolar Status in an Infant with KCNJ11-Related Neonatal Diabetes Mellitus via Continuous Renal Replacement Therapy
}

\author{
Ting Chen (D) - Dandan Zhang - Zhenjiang Bai · Shuiyan Wu • \\ Haiying Wu · Rongrong Xie · Ying Li · Fengyun Wang • \\ Xiuli Chen · Hui Sun · Xiaoyan Wang · Linqi Chen
}

Received: June 21, 2018 / Published online: August 9, 2018

(C) The Author(s) 2018

\section{ABSTRACT}

Neonatal diabetes mellitus (NDM) is a rare monogenic disorder presenting as uncontrolled hyperglycemia during the first 6 months of life. Hyperglycemic hyperosmolar state (HHS) is quite rare in NDM patients, and reported experience with this condition is limited. Continuous renal replacement therapy (CRRT) is frequently used as a mode of dialytic treatment in critically ill patients with acute renal failure, but has seldom been used in patients with diabetic ketoacidosis (DKA) and HHS. We report

Ting Chen and Dandan Zhang contributed equally to this study.

Enhanced digital features To view enhanced digital features for this article go to https://doi.org/10.6084/ m9.figshare.6877106.

Electronic supplementary material The online version of this article (https://doi.org/10.1007/s13300018-0484-3) contains supplementary material, which is available to authorized users.

T. Chen - D. Zhang $\cdot$ H. Wu $\cdot$ R. Xie - F. Wang .

X. Chen · H. Sun $\cdot$ X. Wang $\cdot$ L. Chen $(\varangle)$

Department of Endocrinology, Metabolism and

Genetic Disorders, Children's Hospital of Soochow

University, Suzhou, Jiangsu, China

e-mail: ct1596@126.com; clq631203@aliyun.com

Z. Bai $\cdot$ S. Wu $\cdot$ Y. Li

Department of Intensive Care Unit, Children's

Hospital of Soochow University, Suzhou, Jiangsu, China the case of a 2-month-old infant admitted to our hospital presenting with dyspnea and lethargy. Blood gas showed severe hyperosmotic DKA. After $21 \mathrm{~h}$ of fluid and insulin therapy, the baby presented with increased drowsiness and irregular respiration, which suggested cerebral edema. Moreover, the DKA and HHS were exacerbated. After $18 \mathrm{~h}$ of CRRT, the patient gradually recovered from DKA and HHS. The gene analysis revealed a de novo mutation (c.602G > A (p.R201H)) of the KCNJ11 gene, and oral glibenclamide successfully replaced insulin treatment in the patient.

Keywords: Continuous renal replacement therapy; Diabetic ketoacidosis; Hyperglycemic hyperosmolar state; Neonatal diabetes mellitus

\section{INTRODUCTION}

Neonatal diabetes mellitus (NDM) is a rare monogenic disorder that presents as uncontrolled hyperglycemia during the first 6 months of life and may be either permanent or transient [1]. Signs of NDM include frequent urination, rapid breathing, and dehydration. In some severe cases, NDM may first manifest as diabetic ketoacidosis (DKA). However, hyperglycemic hyperosmolar state (HHS) is rare in NDM patients [2]. 
Gain-of-function heterozygous mutation in the KCNJ11 gene, which encodes one subunit of the ATP-sensitive potassium $\left(\mathrm{K}_{\mathrm{ATP}}\right)$ channel, is a major cause of NDM [3]. Detection of KCNJ11 mutations in NDM patients is of great clinical value since oral sulfonylurea drugs can replace insulin therapy to control hyperglycemia in these patients. Mutations in KCNJ11 can cause a broad spectrum of phenotypes, ranging from isolated transient neonatal diabetes to the most severe cases with neurodevelopmental disability, seizures, and insensitivity to sulfonylurea treatment [4]. Moreover, according to a recent study by Letourneau et al., infants with KCNJ11 mutation-caused NDM tend to have severe hyperglycemia and DKA on presentation [5].

Continuous renal replacement therapy (CRRT) is frequently used as a mode of dialytic treatment in critically ill patients with acute renal failure [6]. Continuous venovenous hemodiafiltration (CVVHDF) is a modality of CRRT that combines both diffusion and convection. The use of CRRT in DKA and HHS has not been well investigated, with only a few cases reported [7-9].

Herein, we present a case of NDM caused by KCNJ11 mutation that presented with an overlap of DKA and HHS and was successfully treated via CRRT.

\section{CASE REPORT}

The girl is the first child of healthy unrelated parents and was born at full term by vaginal delivery. Her birth weight was $2.85 \mathrm{~kg}$. Informed consent was obtained from the individual participant's parents for being included in the study. About half a year ago, the 2-month-old girl presented to our hospital with respiratory distress and poor appetite. On admission, her weight was $4.6 \mathrm{~kg}$. Physical examination showed that she had a fever, tachycardia (heart rate $183 \mathrm{bpm}$ ), tachypnea (breath rate $44 \mathrm{bpm})$, hypoxia $\left(\mathrm{SpO}_{2} 95 \%\right)$, lethargy, and dyspnea. She had sunken eyes, cold and clammy skin, skin pinch going back slowly, and cried without tears. Urine examination showed ketones at $25 \mathrm{mg} / \mathrm{dl}$ and urine glucose at $800 \mathrm{mg} / \mathrm{dl}$. Severe hyperglycemia and acidosis were also detected (glucose $43 \mathrm{mmol} / \mathrm{L}$, blood gas pH 6.87, $\mathrm{HCO}_{3} 5.3 \mathrm{mmol} / \mathrm{L}$, effective osmolality $321 \mathrm{mOsm} / \mathrm{L}$ ) (Fig. 1, Table 1). Insulin was at less than $0.5 \mathrm{mU} / \mathrm{L}$ (range $3-25 \mathrm{mU} /$ $\mathrm{L}$ ); C-peptide was at less than $0.05 \mathrm{ng} / \mathrm{ml}$ (range $0.78-1.89 \mathrm{ng} / \mathrm{ml}$ ); and antibodies for diabetes were negative.

The patient was given oxygen via a nasal catheter $(1 \mathrm{~L} / \mathrm{min})$ and a $50-\mathrm{ml}$ normal saline bolus over $1 \mathrm{~h}$. A double-lumen central line was then placed to allow $48 \mathrm{~h}$ intravenous administration of fluids $(0.45 \%$ saline with potassium chloride, $\quad 5.4-6.5 \mathrm{ml} / \mathrm{kg} / \mathrm{h})$ and insulin $(0.05-0.1 \mathrm{U} / \mathrm{kg} / \mathrm{h})$. During this period, the serum glucose level decreased at a rate of about $1 \mathrm{mmol} / \mathrm{L} / \mathrm{h}$, but the effective osmolality increased at a rate of $0.88 \mathrm{mOsm} / \mathrm{L} / \mathrm{h}$ (Table 1 ). After $20 \mathrm{~h}$, the patient presented with increased drowsiness, dyspnea, and irregular respiration. The signs of dehydration had not improved. To release her dyspnea, she was intubated (SIMV + PS mode). The blood gas revealed more severe acidosis and a hyperosmotic state (glucose $20.6 \mathrm{mmol} / \mathrm{L}, \quad \mathrm{pH} 6.80, \quad \mathrm{HCO}_{3}$ $2.1 \mathrm{mmol} / \mathrm{L}$, effective osmolality $338.6 \mathrm{mOsm} /$ L) (Fig. 1, Table 1). CBC showed decreased $\mathrm{Hb}$ and hematocrit ( $\mathrm{Hb} 72 \mathrm{~g} / \mathrm{L}$, hematocrit 22\%). Liver function showed low albumin $(30.2 \mathrm{~g} / \mathrm{L})$. Thus RBC transfusion was given. After obtaining consent from the girl's parents, CVVHDF was started. The patient underwent $18 \mathrm{~h}$ of CVVHDF using the Prismaflex device (Gambro, Lund, Sweden) with a bicarbonate-buffered replacement fluid (sodium $143 \mathrm{mmol} / \mathrm{L}$, potassium $4.73 \mathrm{mmol} / \mathrm{L}$, chloride $113.3 \mathrm{mmol} / \mathrm{L}$, magnesium $\quad 0.75 \mathrm{mmol} / \mathrm{L}, \quad$ bicarbonate $34.8 \mathrm{mmol} / \mathrm{L}$, glucose $10.0 \mathrm{mmol} / \mathrm{L}$, osmotic pressure $308 \mathrm{mmol} / \mathrm{L}$ ) via a dual-lumen right internal jugular vein catheter. Calcium was administered separately to avoid precipitation. CVVHDF was performed with anticoagulation (heparin $15 \mathrm{U} / \mathrm{kg} / \mathrm{h}$ ), using a high-flux membrane of $0.2 \mathrm{~m}^{2}$ surface area HF 20 filter (Gambro Industries, Lyon, France), at a dose of $22 \mathrm{ml} /$ $\mathrm{kg} / \mathrm{h}$ and blood flow rate of $26 \mathrm{ml} / \mathrm{min}$. After $6 \mathrm{~h}$ of treatment, since the acidosis was not greatly improved, we further increased the concentration of bicarbonate in the replacement fluid (sodium $146.5 \mathrm{mmol} / \mathrm{L}$, potassium $4.73 \mathrm{mmol} /$ $\mathrm{L}$, chloride $112.2 \mathrm{mmol} / \mathrm{L}$, magnesium 

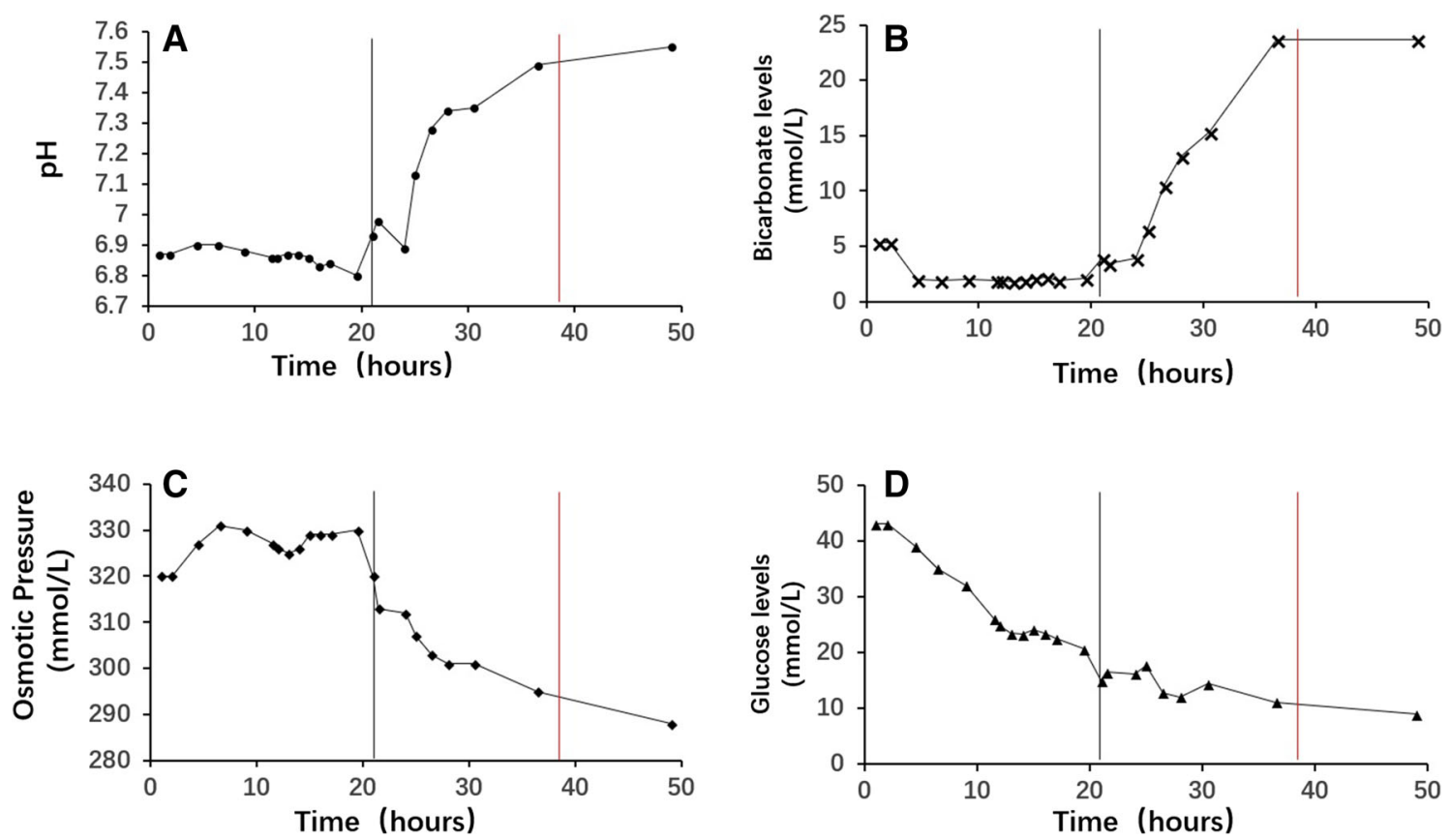

Fig. 1 Blood gas analysis of the patient during the course of treatment. The $\mathrm{pH}$ value, bicarbonate level, osmotic pressure, and glucose levels over the whole course of treatment are show in $\mathbf{a}-\mathbf{d}$, respectively. The black lines

$0.75 \mathrm{mmol} / \mathrm{L}$, bicarbonate $39.0 \mathrm{mmol} / \mathrm{L}$, glucose $10.0 \mathrm{mmol} / \mathrm{L}$, osmotic pressure $314 \mathrm{mmol} / \mathrm{L}$ ). After $18 \mathrm{~h}$ of CVVHDF, DKA and HHS were totally corrected. Signs of dehydration were also corrected. During CRRT, the serum glucose level decreased at a rate of about $0.53 \mathrm{mmol} / \mathrm{L} / \mathrm{h}$, and the effective osmolality decreased at a rate of $2.1 \mathrm{mOsm} / \mathrm{L} / \mathrm{h}$ (Table 1$)$. The next day, we stopped sedative administration, the patient gradually recovered consciousness and autonomous regular respiration, and the mechanical ventilation was then stopped. The patient was then transferred to the department of endocrinology.

The focused exome sequencing revealed a de novo heterozygous mutation in KCNJ11 Exon1 (NM_000525.3: c.602G > A; p. (Arg201His)) in the patient. This mutation was subsequently confirmed by traditional Sanger sequencing in the patient and her parents, which showed that neither of her parents carried this mutation (Fig. 2). During hospitalization, the girl's insulin therapy was gradually replaced by oral glibenclamide (initial dose $0.5 \mathrm{mg}$ po qd, maximum

indicate the start of CRRT, and the red lines indicate the end of CRRT

dose $0.5 \mathrm{mg}$ po tid). Now, only a small amount of glibenclamide is needed ( $0.1 \mathrm{mg}$ po tid) to maintain euglycemia. The patient has normal developmental milestones without any neurodevelopmental disability until the last visit.

\section{DISCUSSION}

In this study, we reported a rare case of NDM caused by KCNJ11 gene mutation that first presented with an overlap of DKA and HHS. Interestingly, when routine fluid and insulin therapy failed to treat DKA and/or HHS, our case suggests that CRRT should be considered in acute management.

The overlap of characteristics of DKA and HHS occurs when patients with HHS have mild or moderate acidosis caused by hypoperfusion/ lactic acidosis or when patients with DKA have severe hyperglycemia. Our patient's disease first manifested as DKA with severe hyperglycemia. After routine fluid and insulin therapy for $20 \mathrm{~h}$, however, the patient developed cerebral and 
Table 1 Biochemical variables of the patient

\begin{tabular}{llllc}
\hline & Onset & Prior to CRRT & At the end of CRRT & Normal range \\
\hline Glucose $(\mathrm{mmol} / \mathrm{L})$ & 43 & 20.6 & 11.1 & $3.92-6.44$ \\
$\mathrm{pH}$ & 6.872 & 6.801 & 7.492 & $7.34-7.45$ \\
$\mathrm{HCO}_{3}^{-}(\mathrm{mmol} / \mathrm{L})$ & 5.3 & 2.1 & 23.7 & $21.4-27.3$ \\
$\mathrm{BE}(\mathrm{mmol} / \mathrm{L})$ & -25.8 & -29.2 & 0.3 & -3.0 to 3.0 \\
${\mathrm{Effective} \mathrm{osmolality}(\mathrm{mOsm} / \mathrm{L})^{\mathrm{a}}}^{-}$ & 321 & 338.6 & 300.4 & $270.0-300.0$ \\
$\mathrm{Corrected} \mathrm{Na}^{+}(\mathrm{mmol} / \mathrm{L})^{\mathrm{b}}$ & 152.4 & 159.4 & 144 & $136.0-145.0$ \\
$\mathrm{~K}^{+}(\mathrm{mmol} / \mathrm{L})$ & 3.9 & 4.9 & 3.2 & $3.50-5.20$ \\
$\mathrm{Cr}(\mu \mathrm{mol} / \mathrm{L})$ & 17.6 & 27.6 & 24.1 & $45-84$ \\
$\mathrm{BUN}(\mathrm{mmol} / \mathrm{L})$ & 7 & 7.64 & 4.89 & $2.90-8.20$ \\
$\mathrm{UA}(\mu \mathrm{mol} / \mathrm{L})$ & 516 & 614.5 & 316.5 & $155-357$ \\
$\mathrm{Hb}(\mathrm{g} / \mathrm{L})$ & 101 & 72 & 96 & $110-140$ \\
$\mathrm{Hematocrit}(\%)$ & 31.9 & 22 & 27.2 & $34-45$ \\
Albumin $(\mathrm{g} / \mathrm{L})$ & 47.6 & 30.2 & 38 & $38-54$ \\
\hline
\end{tabular}

$B E$ base excess, $C r$ creatine, $B U N$ blood urea nitrogen, $U A$ uric acid, $H b$ hemoglobulin

${ }^{a}$ Effective $\mathrm{Osm}=2 \times($ plasma $\mathrm{Na})+$ plasma glucose $\mathrm{mmol} / \mathrm{L}$

b Corrected $\mathrm{Na}^{+}=$measured $\mathrm{Na}+2[($ plasma glucose -5.6$) / 5.6] \mathrm{mmol} / \mathrm{L}$

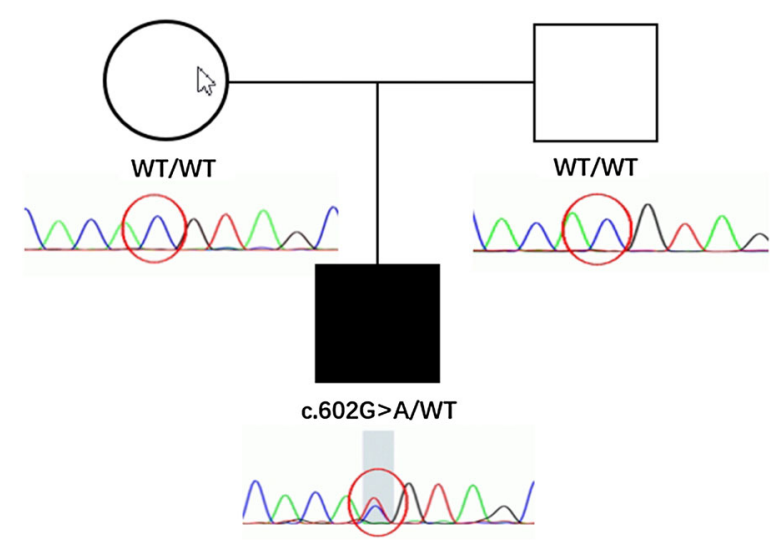

Fig. 2 The family pedigree. The mutation status of KCNJ11 c.602 G > A is indicated by the symbol for each subject. WT indicates wild type. Sanger sequencing of three members of the family in c. 602 position is also indicated under the symbol of each subject. The red circles indicate the mutation points

pulmonary edema, and the ketoacidosis and hyperosmotic state worsened.
Cerebral edema (CE) is the leading cause of DKA death, especially in patients under 5 years old. Our patient experienced sudden disease onset at a very early age, and she had severe hypocapnia and acidosis at presentation, which are all risk factors for CE [2]. After $20 \mathrm{~h}$ of treatment, our patient developed increased drowsiness and irregular respiratory pattern, which implied the presence of CE and was a major cause of the aggravation of her condition. The underlying mechanisms of $\mathrm{CE}$ remain unknown, and previous studies revealed that increased utilization of ketone bodies of immature brains, the low levels of antioxidant defenses in the brain, a more severe systemic immune response and neuroinflammatory responses, the susceptibility of immature blood-brain barrier, and dysfunction of cerebrovascular endothelial cells may contribute to the pathogenesis [10]. Besides, DKA-induced inflammation will increase systemic inflammatory markers, including heat-shock proteins, 
complements, and pro-inflammatory cytokines IL1 $\beta$, IL-2, IL-6, IL8, and TNF- $\alpha[11,12]$.

Pulmonary edema (PE) is a rare complication of DKA, which can cause hypoxemia and needs supplemental oxygenation or intubation in some children [13]. PE is thought to be caused by a fall in hematocrit and colloid pressure during fluid treatment and an increase in the permeability of pulmonary capillary membranes [13]. Moreover, DKA-induced inflammation also plays an important role in the pathogenesis of PE [14]. Our patient had dyspnea on presentation, and the chest X-ray was normal (Suppl. 1). After $20 \mathrm{~h}$ of treatment, her hematocrit and albumin level fell steeply, and her dyspnea was aggravated. Therefore, we supposed that her dyspnea was partly caused by $\mathrm{PE}$, which might also account for the aggravated acidosis in the patient after $20 \mathrm{~h}$ of treatment. A blood transfusion was given to the patient to elevate the hematocrit, and mechanical ventilation helped to maintain normal blood oxygen saturation. After the tracheal tube was removed, the patient recovered without any pulmonary sequelae.

CRRT is suited to the renal support of critically ill patients. The use of CRRT in DKA and/ or HHS is rare, and only limited records are available in the literature [7-9]. CRRT can remove in vivo toxicants and metabolites from patients, as well as correct the disturbance of water and electrolytes effectively. The CVVHDF modality of CRRT can not only eliminate the small molecules such as ketone bodies and glucose but also clear the inflammatory mediators including circulating cytokines and complements efficiently [15]. Therefore, CVVHDF is very suitable for preventing and/or treating cerebral and pulmonary edema, as well as correcting severe DKA and HHS in acute management.

\section{CONCLUSION}

Our observation suggests that CRRT has significant potential in saving critically ill children with cerebral and pulmonary edema caused by severe DKA and/or HHS. However, further studies are still required to assess the value of CRRT in more cases.

\section{ACKNOWLEDGEMENTS}

We thank the patient of the study and all of the doctors and nurses who provided care for her.

Funding. This study was supported by a National Natural Science Foundation of China award (project code 81700793) to Dr Ting Chen, a National Natural Science Foundation of China award (project code 81571551) and a Natural Science Foundation of Jiangsu Province award, China (project code BK20151206) to Zhenjiang Bai. The article processing charges were funded by the authors.

Authorship. All named authors meet the International Committee of Medical Journal Editors (ICMJE) criteria for authorship for this article, take responsibility for the integrity of the work as a whole, and have given their approval for this version to be published.

Disclosures. Ting Chen, Dandan Zhang, Zhenjiang Bai, Shuiyan Wu, Haiying Wu, Rongrong Xie, Ying Li, Fengyun Wang, Xiuli Chen, Hui Sun, Xiaoyan Wang and Linqi Chen have no conflicts to disclose.

Compliance with Ethics Guidelines. The authors received informed consent from the patient's parents for this case report.

Data Availability. All data generated or analyzed during this study are included in this published article/as supplementary information files.

Open Access. This article is distributed under the terms of the Creative Commons Attribution-NonCommercial 4.0 International License (http://creativecommons.org/licenses/ by-nc/4.0/), which permits any noncommercial use, distribution, and reproduction in any medium, provided you give appropriate credit to the original author(s) and the source, provide 
a link to the Creative Commons license, and indicate if changes were made.

\section{REFERENCES}

1. Aguilar-Bryan L, Bryan J. Neonatal diabetes mellitus. Endocr Rev. 2008;29:265-91.

2. Wolfsdorf JI, Allgrove J, Craig ME, et al. Diabetic ketoacidosis and hyperglycemic hyperosmolar state. Pediatr Diabetes. 2014;15:154-79.

3. Babiker T, Vedovato N, Patel K, et al. Successful transfer to sulfonylureas in KCNJ11 neonatal diabetes is determined by the mutation and duration of diabetes. Diabetologia. 2016;59:1162-6.

4. Thurber BW, Carmody D, Tadie EC, et al. Age at the time of sulfonylurea initiation influences treatment outcomes in KCNJ11-related neonatal diabetes. Diabetologia. 2015;58:1430-5.

5. Letourneau LR, Carmody D, Wroblewski K, et al. Diabetes presentation in infancy: high risk of diabetic ketoacidosis. Diabetes Care. 2017;40:e147-8.

6. Tolwani AJ, Campbell RC, Stofan BS, Lai KR, Oster RA, Wille KM. Standard versus high-dose CVVHDF for ICU-related acute renal failure. J Am Soc Nephrol. 2008;19:1233-8.

7. Tang Q, Li Z, Huang D, et al. Continuous renal replacement therapy-the new treatment of serious hyperglycemia. Am J Emerg Med. 2016;34(2469):e3-4.

8. Kawata H, Inui D, Ohto J, et al. The use of continuous hemodiafiltration in a patient with diabetic ketoacidosis. J Anesth. 2006;20:129-31.
9. Mewawalla P, Jaiswal G, Moustakakis M, Sankaranarayanan N, Dasanu CA. Refractory DKA as first presentation of acromegaly and a potential role for continuous venovenous hemofiltration in its successful management. Conn Med. 2011;75:405-7.

10. Hoffman WH, Artlett CM, Boodhoo D, et al. Markers of immune-mediated inflammation in the brains of young adults and adolescents with type 1 diabetes and fatal diabetic ketoacidosis. Is there a difference? Exp Mol Pathol. 2017;102:505-14.

11. Close TE, Cepinskas G, Omatsu T, et al. Diabetic ketoacidosis elicits systemic inflammation associated with cerebrovascular endothelial cell dysfunction. Microcirculation. 2013;20:534-43.

12. Karavanaki K, Karanika E, Georga S, et al. Cytokine response to diabetic ketoacidosis (DKA) in children with type 1 diabetes (T1DM). Endocr $\mathrm{J}$. 2011;58:1045-53.

13. Park JT, Lee $H$, Kee $Y K$, et al. High-dose versus conventional-dose continuous venovenous hemodiafiltration and patient and kidney survival and cytokine removal in sepsis-associated acute kidney injury: a randomized controlled trial. Am J Kidney Dis. 2016;68:599-608.

14. Bialo SR, Agrawal S, Boney CM, Quintos JB. Rare complications of pediatric diabetic ketoacidosis. World J Diabetes. 2015;6:167-74.

15. Hoffman WH, Stamatovic SM, Andjelkovic AV. Inflammatory mediators and blood brain barrier disruption in fatal brain edema of diabetic ketoacidosis. Brain Res. 2009;1254:138-48. 